\title{
SEGURANÇA ALIMENTAR: A ABORDAGEM DOS ALIMENTOS TRANSGÊNICOS
}

\section{FOOD SAFETY: THE APPROACH TO TRANSGENIC FOODS}

\author{
Suzi Barletto CAVALLI'
}

\begin{abstract}
RESUMO
O objetivo desta comunicação é discutir a relação entre a segurança alimentar e os alimentos geneticamente modificados. A biotecnologia e a engenharia genética têm sido encaradas como parte da segunda revolução verde, justificando-se, entre outras prerrogativas, o uso de alimentos transgênicos como solução do problema da fome no mundo, sem risco à saúde da população e ao meio ambiente. Face a essa premissa, discute-se a segurança alimentar sob os enfoques qualitativos e quantitativos, destacando as atribuições dos órgãos responsáveis e suas interfaces com alimentos geneticamente modificados. Acredita-se que os alimentos transgênicos não sejam a solução para o problema da fome no mundo.
\end{abstract}

Termos de indexação: segurança alimentar, alimentos transgênicos, saúde.

\begin{abstract}
The objective of this communication is to discuss the relationship between food safety and genetically modified foods. Biotechnology and genetic engineering are being considered as part of the second green revolution, showing that the use of transgenic foods is the solution for the world's hunger problem, without risk to the population's health and the environment. Because of this matter, food safety is being discussed, not only in qualitative but also in quantitative aspects, emphasizing the attributions of the responsible institutions and their interfaces with genetically modified foods. The transgenic foods are believed not to be the solution of the hunger problem in the world.
\end{abstract}

Index terms: food safety and security, transgenic foods, health.

\section{INTRODUÇÃO}

O termo food safety - alimento seguro - significa garantia do consumo alimentar seguro no âmbito da saúde coletiva, ou seja, são produtos livres de contaminantes de natureza química (agroquímicos), biológicas (organismos patogênicos), física ou de outras substâncias que possam colocar em risco sua saúde (Spers \& Kassouf, 1996). Já o termo food security - segurança alimentar - é a garantia de acesso ao consumo de alimentos e abrange todo o conjunto de necessidades para a obtenção de uma nutrição adequada à saúde. No Brasil utiliza-se a denominação de segurança alimentar para os dois enfoques.

Os programas de segurança alimentar devem propiciar um controle de qualidade efetivo de toda a cadeia alimentar, desde a produção, armazenagem, distribuição até o consumo do alimento in natura ao

\footnotetext{
(1) Departamento de Ciências da Saúde, Curso de Nutrição, Universidade Regional do Estado do Rio Grande do Sul (UNIJUI). Caixa Postal 560, 98700-000, Ijuí, RS Brasil.E-mail:scavalli@unijui.tche.br
} 
processado, bem como os processos de manipulação que se fizerem necessários.

No âmbito internacional, a segurança alimentar é preconizada por organismos e entidades como a Organização para Agricultura e Alimentos (FAO) e a Organização Mundial da Saúde (OMS) World Health... (1996) e no âmbito nacional, o Ministério da Saúde (MS), da Agricultura e Abastecimento (MA) e o Instituto Brasileiro de Defesa do Consumidor (IDEC) são os órgãos responsáveis.

No Brasil, o processo que garante a segurança e a qualidade dos alimentos, por parte do governo, das unidades de produção agropecuária, das indústrias e dos distribuidores, e também dos consumidores, enfrenta dificuldades. As políticas públicas estão cada vez mais orientadas para a descentralização estadual e municipal. A população que exerce e exige o controle de segurança de qualidade dos alimentos, ainda é um contigente pequeno.

Temos no Brasil tanto a fome, a miséria, como a falta de controle de qualidade efetivo, de vital importância para a população. O Ministério da Saúde é responsável pela fiscalização dos produtos industrializados, o qual tem por atribuição o respectivo controle de segurança da qualidade. A Agência Nacional de Vigilância Sanitária (ANVS) coordena o sistema de controle nos serviços de alimentação - food service - envolvendo restaurantes, bares, lanchonetes, empresas de refeições coletivas, panificadoras, lojas de conveniência, mercearias, entre outros.

O Ministério da Agricultura e do Abastecimento realiza a fiscalização e o controle de bebidas e dos produtos de origem animal, este por meio de Serviços de Inspeção Federal (SIF). O MA é responsável pela inspeção e classificação dos produtos agrícolas e também pelo controle da segurança dessa produção. O Brasil, hoje, vincula a segurança e o controle de qualidade de alimentos, alicerçado no mercado internacional, adequando-se ao sistema de controle de exportação (Salay \& Caswell, 1998).

\section{Biotecnologia: a nova revolução verde}

A revolução verde implementada na década de 50, estava fundamentada na produção de larga escala com alta tecnologia, demonstrando como resultado, excelente produtividade. Nos anos 90s, é preconizada a nova revolução verde: revolução genética, unindo a biotecnologia e a engenharia genética, promovendo assim significativas transformações na agricultura mundial.

O aumento da produtividade, a maior resistência às doenças e às pragas, o decréscimo no tempo necessário para produzir e distribuir novos cultivares de plantas, provavelmente com produção de novos organismos vegetais e animais, são alguns ícones que a biotecnologia e a engenharia genética estão criando. Alguns questionamentos são levantados e postos em discussão. De que modo se utilizará a biotecnologia? Quais são os problemas que procura resolver e quem se beneficiará da tecnologia? (Hobbelink, 1990). Quais são as conseqüências ambientais para a saúde pública? (Altieri, 1999).

A primeira e a segunda revolução verde trazem consigo a metáfora do confronto da fome, de como solucionar o problema alimentar no mundo. Neste novo contexto, renasce a crença de que é preciso viabilizar a segunda revolução verde, para solucionar a fome que se configura no momento e a futura. Esse enfoque é largamente utilizado em defesa e justificativa da biotecnologia e da engenharia genética (Fontes, 1998; Pinazza \& Alimandro, 1998).

Várias foram as hipóteses levantadas sobre as causas da fome: falta de produção agrícola (insuficiência de oferta) e problemas na intermediação - distribuição e comercialização (desperdícios e elevação dos preços). Como fator explicativo ao longo da história do país, utilizaram-se essas justificativas, e a partir dos anos 80s, surge a terceira razão, a falta de poder aquisitivo de uma grande parcela da população, face a percepção de que os problemas vinculados anteriormente estavam relativamente equacionados (Graziano da Silva, 1998).

O aumento da produção de alimentos por si só não possibilita a segurança alimentar e nutricional da população, pois o problema da fome não está na disponibilidade alimentar global, mas sim na pobreza de uma grande parte da população (Hoffmann, 1996). Para Sachs (2000), a luta contra a fome não se reduz ao aumento da oferta de alimentos, mas em fornecer condições à população para adquirir ou autoproduzir o seu sustento, o que remete ao emprego gerador de renda, ao auto-emprego e à reforma agrária.

A biotecnologia e engenharia genética como novas tecnologias para a cadeia produtiva, em particular para as companhias oligopólicas desse mercado, são propagadas sob o argumento de não agredirem o ambiente e contribuírem para a saúde, inclusive por contribuírem para o fim do uso de pesticidas e da fome no mundo (Pinazza \& Alimandro, 1998).

O discurso da nova revolução verde como se pode perceber na fala de Norman Bourlaugh, tende a enfatizar a justificativa do combate a fome,

"é preciso enfrentar a realidade, não se pode atrasar o relógio e regressar aos velhos tempos dos anos 30, quando a população mundial era de 2 bilhões de pessoas e se usavam pouco fertilizantes e insumos químicos. Não se pode perder a visão da tarefa descomunal de alimentar 8 a 10 bilhões de pessoas no futuro"... "a biotecnologia seria o caminho para aumentar a oferta de alimentos no mundo" (Souza, 1999b).

Os alimentos geneticamente modificados, bem como a biotecnologia, se sustentam sobre tais argumentos e pela disputa entre as corporações do mercado 
internacional pelos produtos oriundos destas tecnologias, modificando o comércio e o controle específico das cadeias agroalimentares do cenário mundial.

\section{Biotecnologia e Biossegurança}

A FAO considera biossegurança a correlação do uso sadio e sustentável do meio ambiente, dos produtos biotecnológicos e as intercorrências para a saúde da população: biodiversidade e sustentabilidade ambiental, com vistas a segurança alimentar global (Nodari \& Guerra, 2000).

As culturas transgênicas de alimentos autorizados para comercialização são inúmeras: na Argentina, a soja em 1996, o milho e o algodão em 1998; no Canadá, o milho e o algodão em 1996, a canola em 1997, a soja e o melão em 1998, a batata e o trigo em 1999; nos Estados Unidos, o melão, a soja, o tomate, o algodão e a batata em 1994, a canola e o milho em 1995; no Japão, a soja, a canola, a batata e o milho em 1996, o algodão e o tomate em 1997; na União Européia, o tomate e a canola em 1995, a soja em 1996, o milho em 1997, a batata e o algodão em 1998 (Comissão Técnica..., 1999).

O mundo se encontra na era do supermercado transgênico, alimentos com os genes modificados chegam à mesa dos consumidores, como a cenoura mais doce e contendo doses extras de beta-caroteno, o arroz com mais proteínas, a batata com retardo de escurecimento, o melão com maior resistência a doenças, o milho resistente a pragas, a soja com genes de castanha-do-pará que aumenta seu valor nutritivo, o tomate longa vida, tendo sido o primeiro alimento transgênico a ser comercializado e a ervilha com genes que permitem sua conservação por mais tempo.

A Comissão Técnica Nacional de Biossegurança (CTNBio), órgão do Ministério da Ciência e Tecnologia, criada pelo poder executivo, através da Lei no 8.974 de janeiro de 1995 e o Decreto 1.752, de novembro de 1995, o qual dispõe sobre a vinculação, competência e composição, afirma que "a biotecnologia colocará o Brasil em condições de competir em pé de igualdade com as nações mais desenvolvidas, melhorando em qualidade e quantidade a produção de alimentos, permitindo o desenvolvimento de novos medicamentos, vacinas e insumos e trazendo melhoria na qualidade de vida do cidadão brasileiro" (Comissão Técnica..., 1999). Relata ainda, que não há registro de nenhum acidente com produtos desenvolvidos por engenharia genética, que todos os produtos desenvolvidos através dessas técnicas na área de fármacos e agricultura foram produzidos e comercializados com segurança, trazendo benefícios a sociedade (Castro, 1998).

A empresa Monsanto recebeu parecer favorável da CTNBio à produção em escala comercial da semente de soja transgênica Roundup Ready resistente à aplicação de herbicida à base de Glifosate da mesma marca, em dezembro de 1998. O parecer técnico-científico baseia-se na conclusão de que a soja geneticamente modificada não oferece riscos a saúde humana ou animal, e nem ao meio ambiente. A decisão da CTNBio está embasada nos seguintes argumentos: o cultivar da soja não é passível de polinização cruzada com espécies silvestres; não há razões para se prever a sobrevivência de plantas derivadas fora de ambientes agrícolas; não haverá aumento da pressão em relação a seleção sobre as plantas daninhas, com a introdução de cultivares tolerantes ao herbicida Glifosate; não há nenhuma constatação de que a utilização do herbicida Glifosate nas lavouras de soja no Brasil, tenha efeito negativo no processo de fixação biológica de nitrogênio; não há indícios de que o uso de cultivares derivadas dessa linhagem possa alterar o perfil e a dinâmica das populações de insetos associados à cultura de soja convencional; a introdução do transgene não altera as características da composição química da soja, com exceção do acúmulo de proteína transgênica, tendo comprovada sua segurança quanto aos aspectos de toxicidade e de alergenicidade humana e animal (Comissão Técnica..., 1999).

Já o Instituto Brasileiro de Defesa... (1999), salienta os riscos dos alimentos transgênicos, para a saúde da população e para o meio ambiente. Pode ocorrer o aumento das alergias com o consumo dos Organismos Geneticamente Modificados (OGM), pois novos compostos são formados no novo organismo, como proteínas e aminoácidos que ingeridos poderão desencadear processos alérgicos, apontam pesquisas desenvolvidas no Reino Unido e Estados Unidos; aumento de resistência aos antibióticos, pois são inseridos nos alimentos transgênicos genes que podem ser bactérias usadas na produção de antibióticos. Com o consumo pela população desses alimentos, poderá ocorrer resistência a esses medicamentos, reduzindo ou anulando a eficácia dos mesmos. Pode ser desencadeado também, um aumento das substâncias tóxicas quando o gene de uma planta ou de um microorganismo for utilizado em um alimento, e é possível que o nível dessas toxinas aumente inadvertidamente, causando mal às pessoas, aos insetos benéficos e aos animais, citando que já foi constatado com o milho transgênico "Bt", levando a Áustria a proibir o seu plantio. Estudos a respeito têm demonstrado que a inserção de genes resistentes aos agrotóxicos em alguns alimentos transgênicos conferem às pragas e às ervasdaninhas maior resistência, tornando-se super-pragas, desequilibrando os ecossistemas, implicando uso de uma maior quantidade de agrotóxicos, que resultará no aumento de resíduos nos alimentos, rios e solos.

A empresa norte-americana Monsanto contra-argumenta, afirmando que suas pesquisas comprovam que a soja transgênica não apresenta riscos à saúde humana e nem prejuízos à biodiversidade. A soja produzida através da biotecnologia torna viável um novo sistema de controle de plantas daninhas, respeitando às normas de segregação no plantio e a rotulagem dos produtos 
industrializados, com previsão da economia no custo por hectare da nova espécie. O novo foco estratégico é contribuir para que a oferta de alimento seja abundante e que os OGM não interfiram nos sistemas nos quais a vida se baseia (Queiroz, 1998).

\section{Controvérsias e Discussões}

Talvez em nenhum outro momento o mundo científico tenha assistido tantas controvérsias, como as que estão ocorrendo na atualidade sobre a manipulação de genes, curas cromossômicas, plantas e animais produzidos através da biotecnologia. Novos paradigmas científicos estão sendo adotados, os cientistas em todo o mundo procuram desvendar a chave dos seres humanos, animais e vegetais. No momento, os cientistas anunciam a engenharia genética e a biotecnologia como uma nova revolução, configurando-se como uma das maiores conquistas científicas.

Hoffmann (1999), aponta que a ciência jamais foi questionada de forma tão impetuosa ao desvelar os resultados de seus estudos e investigações até o surgimento dos produtos transgênicos.

O novo mercado cresce vertiginosamente e vários são os embates entre companhias, governos, ambientalistas e pesquisadores. Em suplemento especial a Revista Agroanalyis (Reinvenção..., 1999), publicou diversos artigos sobre a temática e a Revista Seed News (2000), várias reportagens. Muitos pronunciamentos também ocorreram por parte de Academias de Ciência de vários países, incluindo a Sociedade Brasileira para o Progresso da Ciência (SBPC), (Royal Society, 2000), e a reunião do G7 - grupo de países mais ricos e industrializados do mundo, mais a Rússia (Silva, 2000). A International Center for Tecnology Assessment (CTA), e a Alliance for Bio-Integraty acionaram judicialmente a Food and Drug Administration (FDA) órgão do governo americano, reivindicando um novo modelo de regulamentção para os alimentos transgênicos. A biossegurança virou batalha internacional, as negociações sobre a regulamentação do comércio de OGM, envolvem bilhões de dólares.

Colombo (1999) afirma que não há vantagens para o consumidor, apenas o produtor tem vantagens econômicas com os OGM. Segundo Neves et al. (2000), o consumidor deve decidir se irá utilizar produtos oriundos ou não da biotecnologia e o setor privado deve ter liberdade na tomada de decisões estratégicas. Souza (1999a), também sugere que a questão dos transgênicos seja discutida mais tecnicamente e divulgada de forma direta para a população.

"Énecessário que todos os produtos transgênicos sejam examinados, avaliados e julgados, caso a caso, tendo em vista a sua finalidade benéfica e que, em concordância com a legislação e baseados nos preceitos éticos, morais, sócio-econômicos e de segurança ambiental, venham garantir vantagens ao consumidor e ao processo produtivo, sem que, no entanto, se ponha em risco a vida e sua evolução como processo dinâmico e multivariável" (Binsfeld, 2000).

A maior discordância ocorre entre os Estados Unidos, que é o maior exportador de produtos desenvolvidos por engenharia genética, e a Europa, que, juntamente com a maioria dos países do terceiro mundo, temem que as lavouras de OGM tenham efeitos devastadores sobre a biodiversidade e as tradições culturais de suas populações.

Greiner (1999) destaca os principais argumentos da rejeição dos alimentos transgênicos na Europa: inexistência da necessidade de produzir alimentos a partir da engenharia genética; riscos, mesmo se considerados hipotéticos; aspecto religioso; efeitos de longo prazo que devem ser estudados e risco ambiental.

Desde a década de 80, organismos internacionais como a Organização para Cooperação Econômica e Desenvolvimento (OECD), FAO e OMS estabeleceram parâmetros para avaliar a segurança alimentar de produtos da tecnologia de DNA/RNA recombinante fundamentando-se no conceito de equivalência (Oda, 1999).

Nodari \& Guerra (2000) relataram que a equivalência substancial (ES) tem sido alvo de críticas pelos cientistas pela falta de critérios mais rigorosos pois, valida o princípio de que alimentos transgênicos são iguais aos convencionais, dispensando a análise de riscos e a rotulagem plena de OGM. A FDA nos Estados Unidos utiliza esta abordagem para os alimentos transgêncos. Este princípio é considerado útil para indústria mas inaceitável do ponto de vista do consumidor e da saúde pública. A defesa de testes biológicos, toxicológicos e imunológicos ao invés da equivalência substancial, é para garantir as análises de existência de toxinas prejudiciais, carcinogênicas e mutagênicas.

Belém et al. (2000) relatam a ocorrência de debates divergentes entre cientistas sobre a biotecnologia e o conceito de ES, no qual os produtos devem apresentar inocuidade, características nutricionais idênticas ao alimento convencional e ausência de efeitos indesejáveis, para poderem ser autorizados para consumo, não previsto explicitamente na legislação brasileira. Millstone et al. (1999) e Burke (1999) sugerem em seus estudos procedimentos para avaliar a ES de plantas geneticamente modificadas e seus derivados.

Na Conferência das Partes, em 1996 na Argentina, foi aprovado o uso das Normas Técnicas em Biossegurança do Programa das Nações Unidas para o Meio Ambiente (PNUMA), fazendo referência a saúde humana e a segurança ambiental na aplicação da biotecnologia, que vai da pesquisa e desenvolvimento até a comercialização dos produtos biotecnológicos (Fontes, 1998).

Em janeiro de 2000, em Montreal, no Canadá, foi assinado por 176 países o Protocolo de Cartagena ou Protocolo Internacional de Biossegurança, o qual permite um controle maior sobre os OGM, pois impõe condições 
para o comércio internacional dos produtos transgênicos, onde os pontos principais são: o princípio de precaução e a rotulagem dos produtos transgênicos (Nodari \& Guerra, 2000). Este princípio, segundo Nodari e Guerra deve ser adotado em caso de dúvida ou falta de conhecimento científico e é uma alternativa que visa proteger a vida, e trata das ações antecipatórias para proteger a saúde das pessoas e dos ecossistemas.

Por decisão do juiz A. S. Prudente, da $6^{\mathrm{a}}$ Vara Federal de Brasília, por ação impetrada pelo IDEC e o Greenpeace, tendo o Instituto Brasileiro do Meio Ambiente e dos Recursos Naturais Renováveis (IBAMA) como litis consorsio, foi suspensa a comercialização das sementes de soja transgênica, enquanto não for realizado o estudo prévio de impacto ambiental e a avaliação de riscos à saúde, além de outras determinações, para a aprovação do plantio no país.

Nodari \& Guerra (2000), declaram que "a verdade atual é a falta de dados científicos que possam permitir uma avaliação conclusiva para esta liberação".

\section{CONSIDERAÇÕES FINAIS}

A revolução genética está apenas começando, implicando em incisivos debates e controvérsias entre a comunidade científica, empresas, órgãos do governo e produtores.

A população, em geral, acompanha a polêmica de forma bastante restrita, pois não conhece bem os efeitos que os alimentos geneticamente modificados podem acarretar em sua saúde. Igualmente não faz parte da cultura do brasileiro exercer um controle de segurança e qualidade sobre os alimentos que consomem, ou exigir dos órgãos competentes a fiscalização do cumprimento da legislação, referente a segurança alimentar.

O IDEC, na sua representação de órgão de defesa do consumidor, está sendo considerado ágil e eficiente diante da problemática e da realidade brasileira, dando ênfase aos direitos básicos do consumidor: direito à informação e o direito de escolha, alicerçado pelo Código de Defesa do Consumidor (CDC). O Instituto analisou trinta e um produtos encontrados no mercado varejista brasileiro e encontrou OGM em nove deles, sendo que cinco eram produtos nacionais e quatro importados. Portanto, está sendo violado o direito previsto no CDC e a decisão judicial em vigor que determina que os alimentos transgênicos estão proibidos no Brasil de serem produzidos e comercializados (Instituto Brasileiro de Defesa..., 2000).

Com relação a rotulagem é imprescindível que os alimentos transgênicos, possuam rótulos com informações ao consumidor, com a identificação dos componentes contidos nos alimentos, à semelhança do que já existe no Brasil em termos de legislação especifica. O Governo Federal, em dezembro de 1999, elaborou proposta de rotulagem de alimentos transgênicos, que até fevereiro de
2000 esteve sob consulta pública. A rotulagem, além de fornecer segurança ao consumidor pelas informações que contêm, possibilita também uma diferenciação de marketing de um produto/marca para outro, desencadeando e aprimorando a concorrência entre os produtores. Há necessidade também de um programa de educação ao consumidor, que possibilite o entendimento da informação para a escolha do alimento através dos rótulos.

Ao liberar o plantio comercial da soja transgênica, a CTNBio reconheceu que havia segurança em relação ao impacto ambiental. Já o fundamento da decisão judicial foi a exigência do Estudo e do Relatório de Impacto Ambiental (EIA - Rima), por entender que esse procedimento é imprescindível. O estudo do impacto ambiental fornecerá elementos que certamente poderão favorecer a preservação do ecossistema podendo inclusive, garantir o desenvolvimento sustentável para a produção de alimentos transgênicos.

Uma série de riscos dos alimentos transgênicos para a saúde estão sendo levantados e questionados, como o aumento das alergias, resistência aos antibióticos, aumento das substâncias tóxicas e dos resíduos nos alimentos. Com relação a segurança alimentar em prol do bem estar da população, é necessário um aprofundamento nas pesquisas, para que se possa consumir esses alimentos sem riscos a saúde.

Questiona-se a garantia da segurança e qualidade alimentar e nutricional dos produtos, bem como, da solução da fome, isto é, como chegar a superação do problema alimentar no mundo. A segurança alimentar pressupõe o direito fundamental de acesso quantitativo e qualitativo de alimentos. Julga-se que não está nos alimentos transgênicos a solução para a erradicação da fome, bem como do oferecimento da segurança alimentar para a população.

\section{REFERÊNCIAS BIBLIOGRÁFICAS}

ALTIERI, M.A. Os mitos da biotecnologia agrícola: alguns questões éticas. O Interior, Porto Alegre, v.25, n.893, p.14-15, 1999.

BELÉM, M.A.F. Equivalência substancial. BioTecnologia Ciência e Desenvolvimento, Brasília, v.3, n.14, p.140-149, 2000.

BINSFELD, P.C. Análise diagnóstica de um produto transgênico. BioTecnologia Ciência e Desenvolvimento, Brasília, v.2, n.12, p.16-19, 2000.

BURKE, D. No GM conspiracy. Nature, London, v.401, p.640, 1999. Disponível em: <www.uol.com.br/idec/>. Acesso em: 16 nov. 2000.

CASTRO, L.A.B. Biossegurança. BioTecnologia Ciência e Desenvolvimento, Brasília, v.2, n.6, p.4-8, 1998.

COLOMBO, C. Futuro dos alimentos transgênicos. Revista Correio Popular. Campinas, n.111, p.5-7, maio 1999.

COMISSÃO TÉCNICA NACIONAL DE BIOSSEGURANÇA. Legislação e Documentos. Disponível em: <www.met.gov.br/ ctnbio/leisedocs>. Acesso em: 15 jul. 1999. 
FONTES, E.M.G. Biossegurança de biotecnologias: breve histórico. Disponível em: <www.met.gov.br/ctnbio/>. Acesso em: 4 nov. 1998.

GRAZIANO DA SILVA, J. A nova dinâmica da agricultura brasileira. Campinas : Unicamp. 1998. 211p.

GREINER, R. Engenharia genética produz alimentos modificados. Notícias SBAN, São Paulo, n.2, p.3-4, 1999.

HOBBELINK, H. Biotecnologia muito além da revolução verde. Porto Alegre : Riocell, 1990. p.109.

HOFFMANN, M.A. Preocupações e conseqüências negativas do uso de plantas transgênicas. Plantio Direto, Passo Fundo, n.51, p.26-28, maio/jun. 1999.

HOFFMANN, R. Pobreza, insegurança alimentar e desnutrição no Brasil. In: GALEAZZI, M.A.M. (Org.). Segurança alimentar e cidadania. Campinas : Mercado de Letras, 1996. p.195-213.

INSTITUTO BRASILEIRO DE DEFESA AO CONSUMIDOR. Alimentos transgênicos? não engula essa! Disponível em: $<$ www.uol.com.br/idec >. Acesso em: 11 jun. 1999.

INSTITUTO BRASILEIRO DE DEFESA AO CONSUMIDOR. Os alimentos geneticamente modificados. Disponível em: <www.uol.com.br/idec>. Acesso em: 16 nov. 2000.

MILLSTONE, E. et al. Beyond substantial equivalence. Disponível em: <www.uol.com.br.idec>. Acesso em: 16 nov. 2000.

NEVES, M.F. et al. Alimentos novos tempos e conceitos na gestão de negócios. São Paulo : Pioneira, 2000.

NODARI, R.O., GUERRA, M.P. Plantas Transgênicas e seus produtos: impactos, riscos e segurança alimentar. In: SIMPÓSIO SUL-BRASILEIRO DE ALIMENTAÇÃO E NUTRIÇÃO: HISTÓRIA, CIÊNCIA E ARTE, 2000, Florianópolis.

ODA, L.M. Alimentos Transgênicos riscos à saúde? Disponível em: <www.met.gov.br/ctnbio>. Acesso em: 3 jul. 1999.
PINAZZA, L.A., ALIMANDRO, R. A Segunda Revolução Verde. Agroanalysis, Rio de Janeiro, v.18, n.10, p.37-43, 1998.

QUEIROZ, A. C. A vida começa aos 97. Frutos da Terra, São Paulo, v.2, n.4, 1998. (Monsanto do Brasil Ltda)

REINVENÇÃO DA VIDA (A). Agroanalysis, Rio de Janeiro, v.19, n.8, p.14-81, 1999. Especial Transgênicos.

ROYAL SOCIETY OF LONDON. Plantas Transgênicas na Agricultura. Disponível em: <www.mct.gov.br>. Acesso em: 16 nov. 2000.

SACHS, I. Rumo à segunda revolução verde. Disponível em: <www.estado.com.br/servicos>. Acesso em: 3 jul. 2000.

SALAY, E., CASWELL, J.A. Developments in Brazilian Food Safety Policy. International Food and Agribusiness Management Review, v.1, n.2, p.167-177, 1998.

SEED NEWS. Transgênicos. Pelotas, v.4, n.5, p.26-38, 2000. Reportagens.

SILVA, A.R. Faltam provas. Agroanalysis, Rio de Janeiro, v.20, n.8, p.59-61, 2000.

SOUZA, A. A polêmica nas lavouras. Panorama Rural, São Paulo, v.1, n.3, p.20-25, 1999 b.

SOUZA, M. Mamão transgênico chega ao campo. BioTecnologia Ciência e Desenvolvimento, Brasília, v.2, n.11, p.4-7, 1999a.

SPERS, E.E., KASSOUF, A.L. A abertura de mercado e a preocupação com a segurança dos alimentos. Higiene Alimentar, São Paulo, v.10, n.46, p.16-26, 1996.

WORLD HEALTH ORGANIZATION. Division of Food and Nutrition. Guidelines for strengthening a National Food Safety Programme. Geneve, 1996.

Recebido em 19 de julho de 2000 e aceito em 11 de janeiro de 2001. 